Article

\title{
Test Data on Intumescent Fire Protection for Structural Steel Sections in Thailand
}

\section{Thanyawat Pothisiri* and Nattawut Hemathulin}

Fire Safety Research Center, Department of Civil Engineering, Faculty of Engineering, Chulalongkorn University, Bangkok, Thailand 10330

E-mail: fcetps@eng.chula.ac.th*

\begin{abstract}
Current fire safety regulations in Thailand require that primary structural steel components of buildings be protected to achieve a minimum of 3-hour fire-resistance rating. For steel roof structures, 1-hour or 2-hour fire-resistance ratings may be specified depending on the number of stories. The verification methods of fire-resistance ratings set forth in the regulations are ISO 834 and ASTM E119 standards. The current trend of fire protection system for steel structures is intumescent paint due to aesthetical reasons. However, the fire-resistance ratings attained by proprietary intumescent systems currently available in the market are inconclusive. It is therefore the aim of this paper to provide an insight of the fire-resistance ratings of different intumescent products based on the data collected from the fire tests conducted by the Fire Safety Research Center of Chulalongkorn University during the period of 2009 - 2011. A statistical analysis was also conducted to compare the test data with the fire-resistance ratings specified in the current fire safety regulations.
\end{abstract}

Keywords: Steel, intumescent, fire resistance, fire safety.

ENGINEERING JOURNAL Volume 16 Issue 2

Received 2 November 2011

Accepted 17 January 2012

Published 1 April 2012

Online at http://www.engj.org

DOI:10.4186/ej.2012.16.2.85 


\section{Introduction}

Fire safety regulations for structural components of buildings in Thailand are generally based on the requirements set forth in Ministerial Regulation (MR) 60, B.E. 2549, issued by the Ministry of Interior. According to MR 60, primary structural components-which are steel columns and beams-that are not protected by concrete covering must be protected by other means to meet a minimum of 3-hour fireresistance rating. For steel roof structures, a minimum of 1-hour fire-resistance rating is specified if the buildings are one-story high, otherwise a minimum of 2-hour fire-resistance rating is required. The fireresistance rating of steel roof structures can be exempt for buildings with less than 1,000 square meters of occupancy area, or the clearance height of the roof structure exceeds 8 meters provided that the buildings are equipped with automatic sprinkler system. The standards referred in MR 60 for the verification of fire resistance ratings are ISO 834 [1] and ASTM E119 [2].

It is well known that unprotected steel members can heat up at approximately the same rate as the surrounding temperature rise, especially for thin sections with a large exposed surface area [3]. To achieve the fire-resistance ratings specified by the current building regulations thus requires that the steel structures be protected. Many alternative methods for fire protection of steelwork have been adopted in Thailand. A traditional method is encasement in poured concrete. This system has not been widely used due to economic and aesthetic reasons. Board systems and spray-on systems have also been introduced in the market in the past few decades. However, these systems are not popular among architects based on the aesthetic point of view.

The current trend of fire protection system for steel structures is intumescent paint. Intumescent paint is a special material that expands into an insulating foam layer upon being heated. The paint may be waterbased or solvent-based and several coats of paint must generally be applied to obtain the required thickness. The key advantage of intumescent paints is that they allow the structural steel members to be seen directly, without any covering other than the paint. However, the fire-resistance ratings attained by proprietary intumescent systems currently available in the market are inconclusive. It is therefore the aim of this paper to provide an insight of the fire-resistance ratings of different intumescent products based on the data collected from the fire tests conducted by the Fire Safety Research Center of Chulalongkorn University during a 3-year period (2009 - 2011). A statistical analysis was also conducted to compare the test data with the fire-resistance ratings specified in the current fire safety regulations.

\section{Fire-Resistance Test Data}

The data presented in this paper were collected based mainly on the test results obtained from a series of fire-resistance tests conducted at the Fire Safety Research Center (FSRC) during the period of 2009 - 2011 with a permission granted by the Department of Civil Engineering, Chulalongkorn University. The following paragraphs describe details of the test set-up and equipment.

The test furnace of FSRC is equipped with six LPG-fueled burners located at two different levels as illustrated in Fig. 1. There are six thermocouples installed alongside the burners to monitor the temperature distribution inside the furnace chamber during the fire test. The internal dimensions of the furnace chamber are $900 \mathrm{~mm} \times 2500 \mathrm{~mm} \times 1700 \mathrm{~mm}$. For the test data considered herein, the time-temperature relationship inside the furnace was controlled to follow ASTM E119 standard fire curve.

The specimens were structural steel members of Grade ASTM A36 with varying cross sections as shown in Table 1 . The steel members were protected with 15 different proprietary intumescent systems from 9 companies. Detailed specifications of each intumescent product were intentionally excluded from this paper to preserve identities of these companies. Because the rate of temperature rise of a protected structural steel member-i.e., the fire-resistance rating - is inversely proportional to the section factor, which is a measure of the ratio of the heated perimeter $H_{p}$ to the area of the cross section $A$ [4], the definition of section factor was also provided in Table 1. The length of the specimens was fixed at 1000 $\mathrm{mm}$ to enable them to fit within the test furnace. Each specimen was installed by bolts to the lid of the furnace such that all sides were exposed to heat while the ends of the specimen were protected with thermal insulation to limit direct heat transfer from the furnace. The alternative test procedure as specified in ASTM E119 was used to evaluate the protection of steel sections without application of design load. Temperatures of the steel were measured with not fewer than three thermocouples at each of two levels 
located $300 \mathrm{~mm}$ from the ends of the steel member. Typical thermocouple distributions are shown in Fig. 2. The fire-resistance rating was determined as the period of fire exposure for which the transmission of heat through the protection did not raise the average temperature of the steel at any one of the two levels above $538^{\circ} \mathrm{C}$, or did not raise the temperature above $649^{\circ} \mathrm{C}$ at any one of the measured points.

The fire-resistance rating (FRR) data were plotted with respect to the section factor as shown in Fig. 3. The FRR data set contains the test results of 138 I-shaped sections (with coating thicknesses in the range of $523-9907 \mu \mathrm{m}$ ), 8 L-shaped sections (with coating thicknesses in the range of $1186-2912 \mu \mathrm{m}$ ), 7 rectangular hollow structural sections (with coating thicknesses in the range of $2116-5019 \mu \mathrm{m}$ ) and 3 circular hollow structural sections (with coating thicknesses in the range of $3121-5110 \mu \mathrm{m}$ ). It can be seen from the figure that, for I-shaped sections, $11.6 \%(16 / 138)$ of the test data fall below the 1-hour FRR criterion while $87 \%(120 / 138)$ and $99.3 \%(137 / 138)$ of the test data fall below the 2-hour and 3-hour FRR criteria, respectively. For L-shaped sections, $75 \%(6 / 8)$ and $100 \%(8 / 8)$ of the test data fall below the 1 hour and 2-hour FRR criteria, while for rectangular hollow structural sections 42.9\% (3/7) and 100\% (7/7) of the test data fall below the 1-hour and 2-hour FRR criteria. For circular hollow structural sections, however, 100\% (3/3) of the test data fall within the 1-hour and 2-hour FRR criteria. To examine the FRR data in probabilistic terms, a more rigorous statistical analysis was performed in the subsequent sections.

It should be noted herein that the FRR data used for the current study were collected from a series of approval tests in which the key objective of these tests was to identify whether the intumescent product could satisfy the FRR requirements specified in MR 60 (1-hour, 2-hour or 3-hour fire-resistance ratings). The thicknesses of each proprietary intumescent product were specified by the sponsoring company specifically for the individual steel sections to be tested. The aim of the current study is neither to investigate the variation of FRR with respect to the types of intumescent systems or the coating thickness, but rather to investigate FRR as a targeted variable. As such, in the following section the FRR data were treated as independent variables regardless of the coating thickness and the section factor.

\section{Statistical Data Analysis}

This section provides details for evaluating the fire-resistance ratings (FRRs) of steel members protected with different intumescent systems. Because the underlying distribution of the FRR data set is not known, a normal distribution is assumed and the Kolmogorov-Smimov goodness-of-fit test [5] is implemented to verify the distribution assumption.

The set of observed FRR data can be rearranged in increasing order, $x_{1}, x_{2}, \ldots, x_{n}$, where $x_{i}$ represents an $i$-th FRR data point and $n$ is the sample size $(n=156)$. From the ordered sample data, a step-wise empirical distribution function is obtained by the proportion of the data smaller than $x_{i}$ in the data set.

$$
F_{n}\left(x_{i}\right)=\frac{\# \text { of } x^{\prime} \mathrm{s} \leq x_{i}}{n}=\frac{i}{n} ; \quad i=1, \ldots, n
$$

The measure of discrepancy, $D_{n}$, between the assumed normal distribution function $F_{0}\left(x_{i}\right)$ having a mean of $\mu=90.2$ and a standard deviation of $\sigma=28.9$, as computed from the FRR data set, and the empirical function $F_{n}\left(x_{i}\right)$ can be computed as follows:

$$
D_{n}=\max _{x_{i}}\left|F_{0}\left(x_{i}\right)-F_{n}\left(x_{i}\right)\right|
$$

For a specified significance level $\alpha=0.05$, the critical value $D_{n}^{\alpha}$ can be obtained from the literature [5] through the following relationship (for $n>50$ ): 


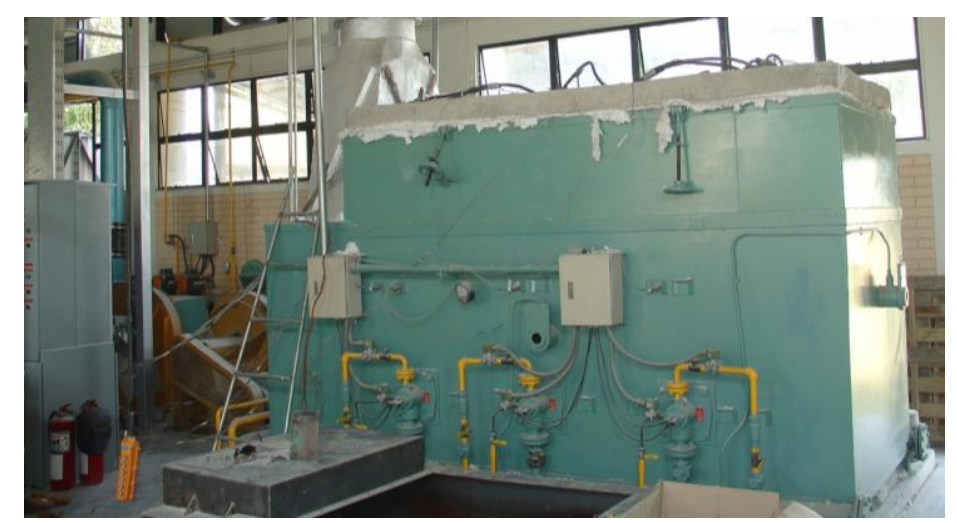

Fig. 1. Test furnace at Fire Safety Research Center (FSRC).

Table 1. Typical steel sections and definition of section factor.

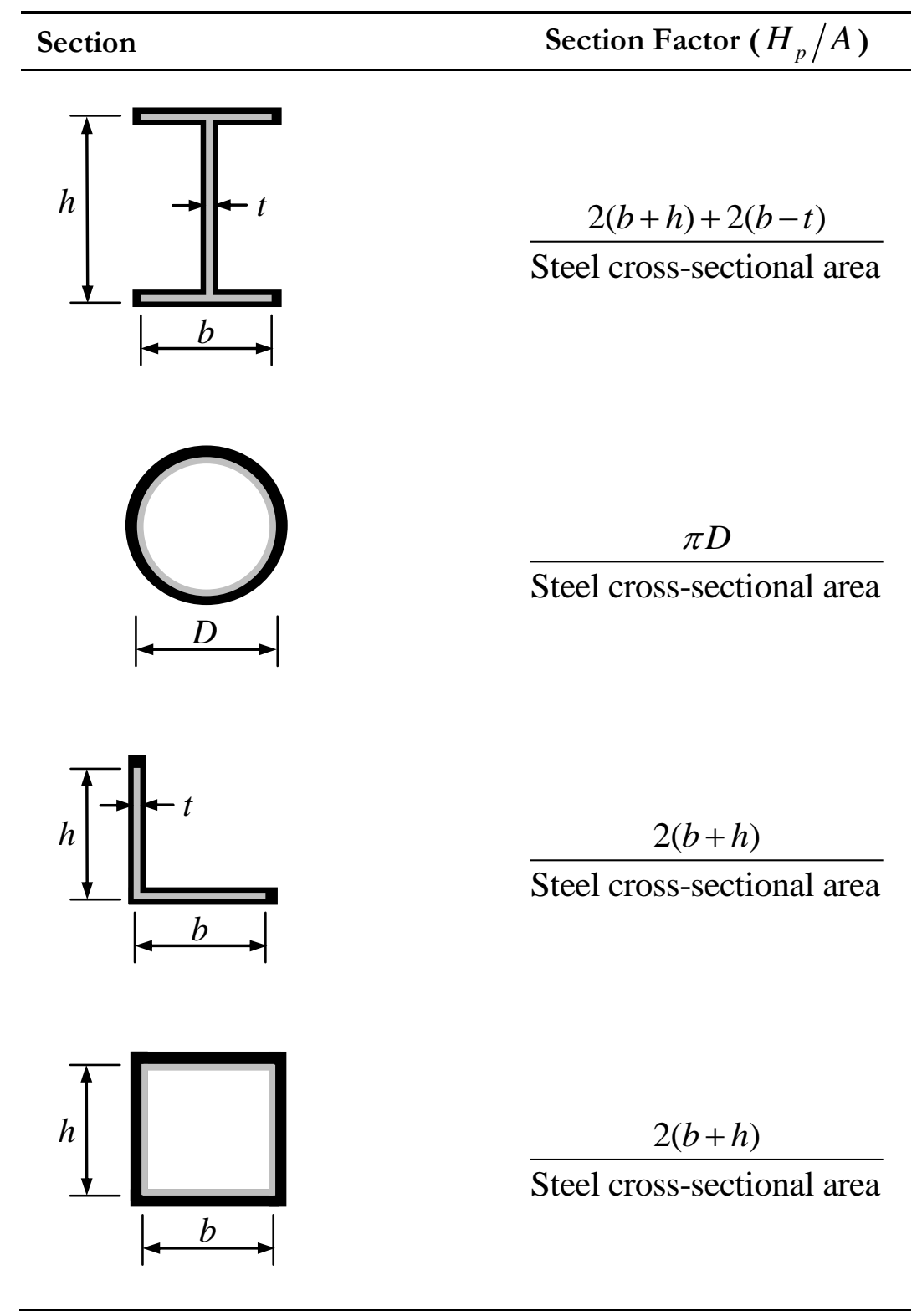




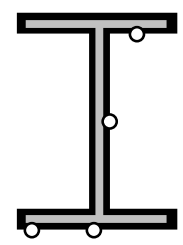

Section A

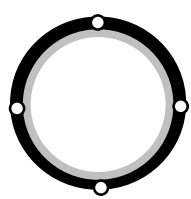

Section A

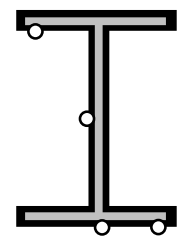

Section B

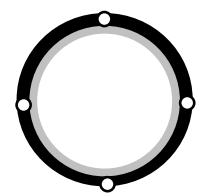

Section B

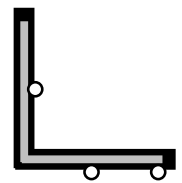

Section A

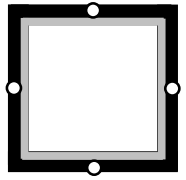

Section A

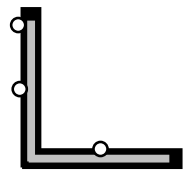

Section B

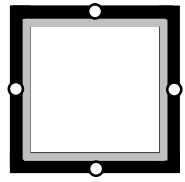

Section B

A $\quad$ B

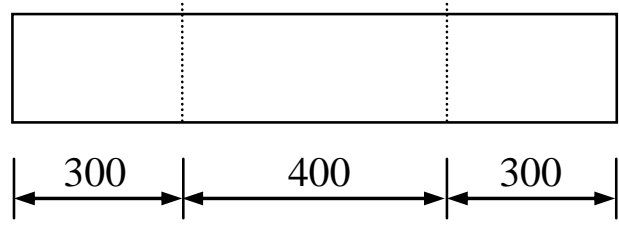

$\underline{\text { Unit (millimeters) }}$

Fig. 2. Typical locations of thermocouples.

$$
D_{n}^{\alpha}=\frac{1.36}{\sqrt{n}}
$$

The assumed distribution is acceptable if the observed $D_{n}$ is less than the critical value $D_{n}^{\alpha}$.

Based on the Kolmogorov-Smirnov goodness-of-fit test, it can be seen that the distribution of the FRR data set is normal as illustrated in Fig. 4.

As previously discussed, the FRR data set can be characterized by a normal distribution with $\mu=90.2$ and $\sigma=28.9$. With the known statistical distribution, the probability that the fire-resistance rating would be less than 1 hour, 2 hours and 3 hours can be computed as 0.148, 0.848 and 0.999 , respectively. The results can be perceived from two different angles. On one hand, it is obvious that engineers must be aware of the possibilities that the intumescent fire protection systems may not satisfy the requirements specified in MR 60. On the other hand, given that most of the proprietary intumescent systems are imported and have been certified for use in other countries, it may be useful to re-examine the current regulations regarding fireresistance ratings. The 3-hour fire-resistance rating requirement seems virtually unachievable for intumescent fire protection systems. 

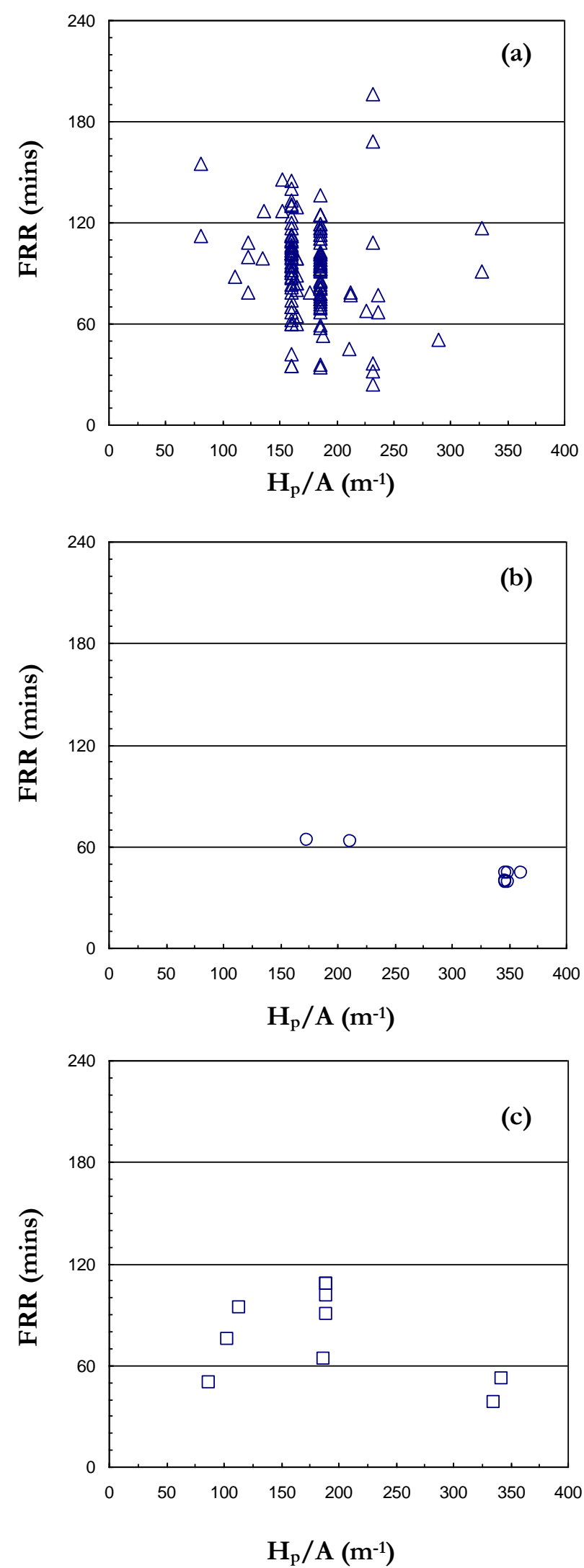

Fig. 3. Variation of FRR data with respect to section factor for different sections: (a) I-shaped sections; (b) L-shaped sections and (c) rectangular and circular hollow structural sections. 


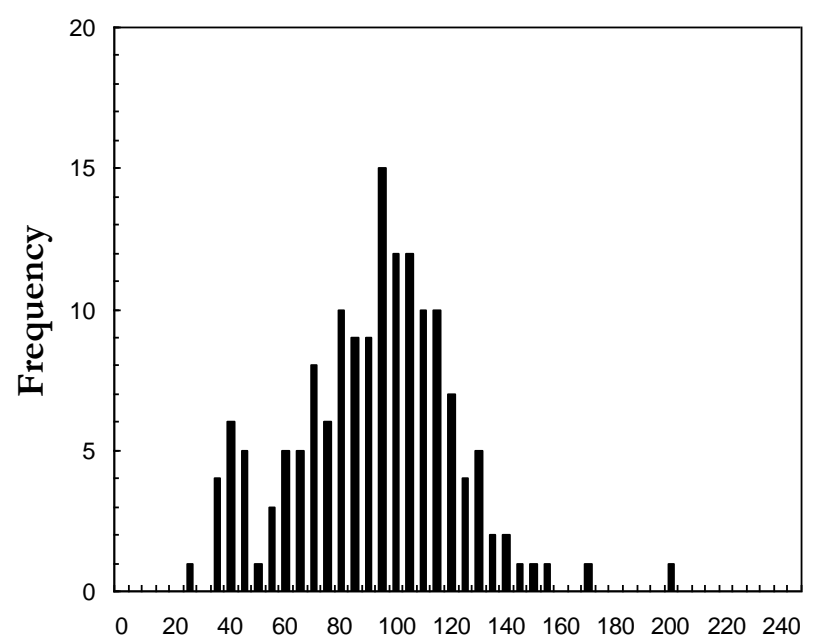

FRR (mins)

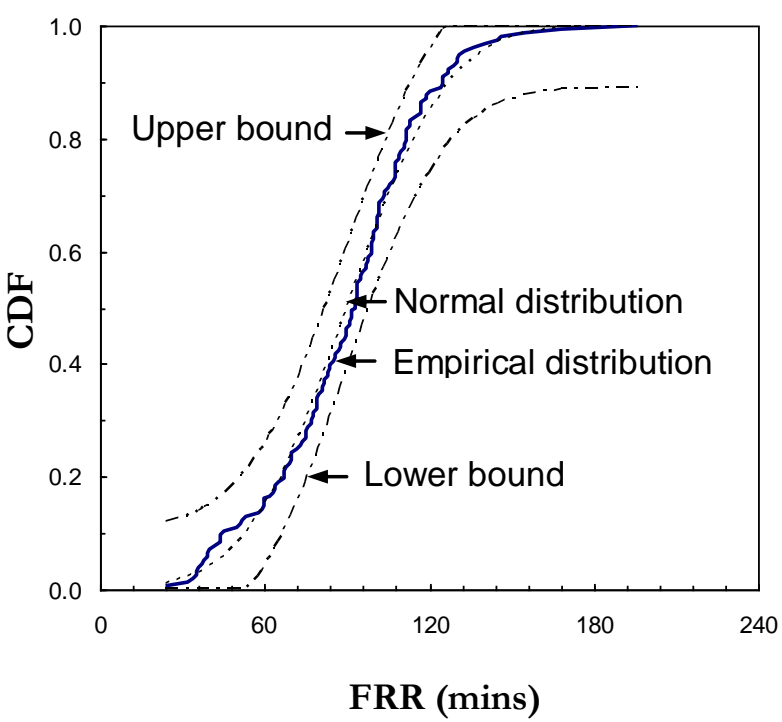

FRR (mins)

Fig. 4. Histogram and cumulative distribution function (CDF) derived from the FRR data set.

\section{Conclusions}

Fire-resistance rating (FRR) data have been collected based on a series of fire tests conducted at the Fire Safety Research Center of Chulalongkorn University during the period of 2009 - 2011. The FRR data were compiled for 138 I-shaped sections, 8 L-shaped sections, 7 rectangular hollow structural sections and 3 circular hollow structural sections protected with 15 proprietary intumescent systems provided by 9 companies. The time-temperature relationships during the fire tests were controlled to follow ASTM E119 standard in which the fire-resistance rating was defined as the time that the average temperature of the steel at any one of the measured levels rose above $538^{\circ} \mathrm{C}$, or the temperature at any one of the measured points rose above $649^{\circ} \mathrm{C}$.

Based on the FRR data set, it has been found that $88.4 \%$ of I-shaped sections, $25 \%$ of L-shaped sections, $57.1 \%$ of rectangular hollow structural sections and $100 \%$ of circular hollow structural sections were able to meet the 1-hour FRR criterion. The percentages drop to 13\% for I-shaped sections and $0 \%$ for other sections when the 2-hour FRR criterion is considered.

The Kolmogorov-Smirnov goodness-of-fit test was also performed on the FRR data set. It has been found that the data can be characterized by a normal distribution with $\mu=90.2$ and $\sigma=28.9$. Based on the derived statistical distribution, the probability that the fire-resistance ratings obtained by any of the intumescent systems tested would be less than 1 hour, 2 hours and 3 hours can be computed as 0.148 , 0.848 and 0.999 , respectively. It can thus be concluded that care must be taken in using intumescent systems to meet the FRR requirements set forth in the current regulations.

\section{Acknowledgement}

The work presented in this paper was financially supported by Stimulus Package 2 (SP2) of Ministry of Education under the theme of Green Engineering for Green Society. 


\section{References}

[1] ISO, "Fire resistance tests-elements of building construction," ISO 834-1999, International Organization for Standardization, 1999.

[2] ASTM, "Standard test methods for fire tests of building construction and materials," ASTM E1192007, American Society for Testing and Materials, 2007.

[3] A. H. Buchanan, Structural Design for Fire Safety, John Wiley \& Sons Ltd, 2002.

[4] J. A. Purkiss, Fire Safety Engineering Design of Structures, Butterworth-Heinemann, Oxford, UK, 2007.

[5] A. H-S. Ang and W. H. Tang, Probability Concepts in Engineering Planning and Design Volume I Basic Principles, John Wiley \& Sons Ltd, 1975. 